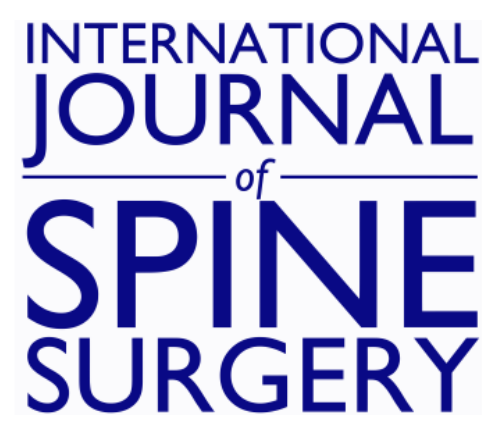

\title{
A Systematic Review and Meta-Analysis of Outcomes and Adverse Events for Juxtafacet Cysts Treatment
}

Enrico Giordan, Paolo Gallinaro, Altin Stafa, Giuseppe Canova, Roberto Zanata, Elisabetta Marton and Jacopo Del Verme

Int J Spine Surg published online 25 February 2022

http://ijssurgery.com/content/early/2022/02/22/8181

This information is current as of April 26, 2023.

Email Alerts Receive free email-alerts when new articles cite this article. Sign up at:

http://ijssurgery.com/alerts

The International Journal of Spine Surgery

2397 Waterbury Circle, Suite 1,

Aurora, IL 60504, Phone: +1-630-375-1432 


\title{
A Systematic Review and Meta-Analysis of Outcomes and Adverse Events for Juxtafacet Cysts Treatment
}

\author{
ENRICO GIORDAN, MD ${ }^{1}$; PAOLO GALLINARO, MD ${ }^{1}$; ALTIN STAFA, MD ${ }^{2}$; GIUSEPPE CANOVA, MD ${ }^{1}$; \\ ROBERTO ZANATA, MD ${ }^{1}$; ELISABETTA MARTON, MD ${ }^{1,3}$; AND JACOPO DEL VERME, MD ${ }^{1}$ \\ ${ }^{I}$ Department of Neurosurgery, Aulss 2 Marca Trevigiana, Treviso, Veneto, Italy; ${ }^{2}$ Department of Neuroradiology, Aulss2 Marca Trevigiana, Treviso, Italy; ${ }^{3}$ Department \\ of Neuroscience, University of Padova, Padova, Italy
}

\begin{abstract}
Background: Different procedures have been used for the treatment of lumbar juxtafacet cysts (JFCs). Recently, fullendoscopic cyst excision has been suggested as a reasonable alternative. We performed a meta-analysis to assess the overall rates of favorable outcomes and adverse events for each available treatment and determine the outcome and complication rates concerning spine stability.

Methods: Multiple databases were searched for English-language studies involving adult patients with lumbar JFCs who had been followed for more than 6 months. Outcomes included the proportion of patients with a satisfactory outcome. Adverse events included recurrence and revision rates as well as intraoperative complications. We further stratified the analysis based on the spine's condition (degenerative listhesis vs without degenerative listhesis).

Results: A total of 43 studies, including 2226 patients, were identified. Over $80 \%$ of patients experienced satisfactory improvement after surgical excision but only $66.2 \%$ after percutaneous cyst rupture and aspiration. Overall, recurrence and revision rates were almost double in patients with preoperative degenerative listhesis at the cyst level, especially in the minimally invasive group ( $2.1 \%$ vs $31.3 \%$ and $6.8 \%$ vs $13.1 \%$, respectively). The rate of full-endoscopic satisfactory outcomes was approximately $90 \%$, with low rates of adverse events $(<2 \%)$.
\end{abstract}

Conclusion: We analyzed the outcome and adverse event rates for each kind of available treatment for JFC. Full endoscopy has outcomes and rates of adverse events that overlap with open and minimally invasive approaches.

Level of Evidence: 2A.

Endoscopic Minimally Invasive Surgery

Keywords: juxtafacet cyst, lumbar, synovial cyst, endoscopic, spine, minimally invasive, percutaneous, cyst rupture

\section{INTRODUCTION}

Lumbar juxtafacet cysts (JFCs) are common in patients with degenerative spine disease and are responsible for radicular pain and neurological symptoms. The development of JFCs is linked to degenerative spondylosis, segmental instability, and trauma. ${ }^{1-3}$ The reported incidence of JFCs among patients undergoing lumbar surgery ranges from $0.1 \%$ to $0.8 \%$, and degenerative listhesis is estimated to be present in $38 \%$ to $75 \%$ of these patients. ${ }^{4,5}$

JFC treatment's mainstay is laminectomy/hemilaminectomy and cyst excision, sometimes coupled with total facetectomy and fusion. ${ }^{6}$ Conservative management or percutaneous cyst rupture and aspiration, ${ }^{7}$ typically used in the elderly or those unwilling or unsuited for surgical treatment, ${ }^{8}$ is mostly temporarily effective and has high recurrence rates. ${ }^{9-12}$

Recently, minimally invasive techniques have been used to treat such patients, expanding spinal surgeons' therapeutic choices. ${ }^{13}$ The full-endoscopic approach has also gained importance in the surgeon's armamentarium and, more recently, has been used for degenerative disease treatment. ${ }^{14}$

Several studies have tried to review and compare the outcomes and adverse events of different surgical techniques for JFCs. ${ }^{15-17}$ However, because some of these studies did not report results per the surgical procedure, they lacked detailed information about their possible outcomes. This is especially true regarding patient selection based on suspected spine instability at the cyst level. Therefore, we restricted our literature analysis to studies with detailed information about surgical management and spine stability to compare actual surgical options. For the first time in literature, this resulted in an extensive stratified analysis of outcomes and adverse events for each type of procedure: open, minimally invasive, percutaneous, and full-endoscopic management of lumbar JFCs.

\section{METHODS}

A comprehensive search of several databases (ie, PubMed, Epub Ahead of Print, Ovid MEDLINE 
In-Process \& Other Non-Indexed Citations, Ovid MEDLINE, Ovid EMBASE, Ovid Cochrane Central Register of Controlled Trials, Ovid Cochrane Database of Systematic Reviews, and Scopus) was conducted with the help of an expert medical reference librarian. The search terms were "juxtafacet cyst," "synovial," "ganglion," "lumbar," "lumbar cysts," "cyst," and "spinal cyst," which were used alone and in combination. Controlled vocabulary supplemented with the keywords was used to search for JFC formation in patients diagnosed with degenerative spinal diseases.

Inclusion criteria were as follows:

1. description of JFCs in both longitudinal and retrospective series that discussed the following:

- synovial cysts in continuity with the capsule of the facet joints

- ganglion cyst

2. $\geq 5$ patients

3. mean or median follow-up $<6$ months

4. published in English between January 2000 and April 2020

5. consecutive series of patients treated with the following:

percutaneous techniques (cyst rupture and aspiration)

open surgery (interlaminar approach or laminectomy/hemilaminectomy and cyst excision)

- minimally invasive approaches (ipsilateral or contralateral microsurgical tubular approaches) full-endoscopic surgery (interlaminar and/or transforaminal full-endoscopic access)

6. intraoperative or histological confirmation of JFCs

7. preoperative imaging adequate to assess spinal stability (either spine CT or MRI and dynamic xray)

8. patients who did not undergo instrumented fusion at the cyst level

9. patients with or without preoperative degenerative listhesis at cyst level

Studies dealing with patients with higher than grade I preoperative degenerative listhesis based on the Meyerding classification, ${ }^{18}$ with vertebral body slippage confirmed through dynamic x-rays or in case of isthmic spondylolisthesis, were excluded. Among these patients, the spine was considered severely unstable and suitable only for fusion procedures, thus perceiving cyst formation as an epiphenomenon of severe spinal instability. Studies with patients who underwent prior instrumented fusion at the cyst level were excluded.

\section{Data Abstraction}

We categorized the studies into 4 groups based on surgical technique, including patients who underwent either surgical or microsurgical cyst excision in the open surgery group. We included studies on patients who underwent microsurgical cyst excision with tubular retraction system in the minimally invasive group. The full-endoscopic group included those studies with patients who underwent endoscopic interlaminar or transforaminal approaches. In the percutaneous group, we included studies only on patients who had undergone computed tomography (CT or fluoroscopically guided JFC rupture and aspiration).

For each study, we extracted the following data: patient's age (years), sex, JFC level, operative time (minutes), hospitalization time (days), follow-up (months), overall outcome, description of the procedure, intraoperative adverse events, whether the adverse events (both medical and surgical) manifested after more than 30 days, same-level JFC recurrence, the proportion of patients with preoperative spinal instability, method of assessing spinal instability (ie, spine CT, dynamic x-rays, or spine magnetic resonance imaging [MRI]), time from lumbar cyst treatment to the development of spinal instability at the affected level (months), and the proportion of patients requiring revision surgery for recurrence or developing instability at the treated level. We noted the surgical approach utilized for each surgical procedure (open vs minimally invasive vs full endoscopic vs percutaneous). We excluded patients with prior fusion surgery at the level of the JFC, but we collected the percentage of patients undergoing fusion surgery either at the surgery time or at developing instability.

The outcomes were defined as "satisfactory" based on MacNab or modified MacNab criteria, ${ }^{19}$ and the values were collected at the last follow-up visit or at least 6 months after the intervention. Only excellent and good scores were considered satisfactory. In some studies, we extracted the degree of postoperative satisfaction ("excellent" and "good") from scores or scales similar to or attributable to MacNab's criteria.

We included preoperative degenerative listhesis when the listhesis at the cyst level described in the pooled studies was within: (1) Meyerding grade 1 
and (2) without vertebral body slippage on dynamic lumbar x-ray.

Every other intervention at the previously treated level or additional arthrodesis to overcome a developing spinal instability was considered as "revision surgery." In the percutaneous group, revisions were divided into 2 subgroups: those needing an additional percutaneous cyst puncture and those requiring surgical cyst excision for symptom control. The following intraoperative adverse events were considered: nerve root damage, dural tear, seroma, and epidural hematoma.

When possible, we separately extracted the subpopulations of patients with confirmed preoperative degenerative listhesis from the investigated segment, calculating outcomes and adverse events for each population (no signs of preoperative degenerative listhesis or instability vs preoperative degenerative listhesis). We also abstracted the mean interval between the first surgery and the development of a more severe degree of spinal instability (ie, Meyerding grade $<$ I or significant mobility in dynamic $\mathrm{x}$-rays).

\section{Study Evaluation}

For each study, we evaluated the design, population, and imaging used in the follow-up. We also evaluated the risk of bias with a modified New Castle-Ottawa Quality Assessment Scale. ${ }^{20}$ The risk of bias was assessed based on the following questions: Did the study include all patients or consecutive patients with adequate radiological follow-up (spine MRI, CT, and dynamic x-rays)? Was the follow-up enough to ascertain the development of spinal instability or cysts recurrence $(<24$ months)? Was histological confirmation reported? (the histological confirmation is a measure of the original study's methodological quality; also, JFCs may have different presentation stages [from fluid to sclerotic content], and histology may help to confirm JFCs excision). The studies were divided into "high" ( $\geq 6$ points), "moderate" ( 4 or 5 points), and "low" $\leq 3$ points) risk of bias categories, and 2 tiers were separately compared and analyzed to see whether there was any statistically significant difference between each (Table 1). Low risk of bias studies was defined as those with a predefined study protocol (randomized or prospective) and adequate imaging follow-up (spine MRI, CT, and dynamic $\mathrm{x}$-rays; follow-up $<24$ months).

\section{Statistical Analysis}

Descriptive statistics were reported as a mean/range for continuous variables and proportion/percentage for categorical variables. For each technique, the proportion of patients considered improved and with adverse events was estimated. Estimates from each cohort were pooled in a random-effects meta-analysis model, as described by DerSimonian and Laird. Anticipating heterogeneity between studies, we chose this model a priori because it incorporates within- and betweenstudy variance. In addition, because in some studies, the rate of outcomes was close to 0 or 1 , the FreemanTukey double-arcsine transformation was utilized. We then made pairwise comparisons between groups for the respective outcomes. All statistical analyses were performed using Stata version 13.0 (StataCorp LLC, College Station, TX).

\section{RESULTS}

\section{Literature Search and Study Characteristics}

The initial literature search yielded 638 articles. Upon review of abstracts and titles, 540 were excluded. In full-text review, 53 more articles were excluded because they did not match the eligibility criteria for this meta-analysis, mainly including the length of follow-up, an adequate definition of lumbar JFCs, or surgical outcomes definition (Figure 1).

Forty-three studies, with 2226 patients, describing outcomes and adverse events of JFC treatment were included. Eighteen of these studies report outcomes after open surgery (1112 patients), 7 exclusively concern minimally invasive treatment (276 patients), 8 used full-endoscopic treatment (233 patients), and 7 used percutaneous rupture and aspiration procedures (477 patients). Three studies compare different kinds of surgical treatment: 1 study compares outcomes between full-endoscopic and open surgery (60 patients) and 1 study compares outcomes between percutaneous techniques and open surgery (45 patients). In another study reporting individual patient data, we were able to extract and separately analyze the outcomes of open vs minimally invasive approaches (23 patients).

Thirty-four studies were retrospective and 9 prospective. Of the 43 studies included in our metaanalysis, 5 had a high risk of bias, 25 had a moderate risk, and 13 had a low risk of bias.

A study-selection flow diagram compiled following the PRISMA guidelines ${ }^{21}$ is provided in Figure 1. A summary of the included studies is provided in 


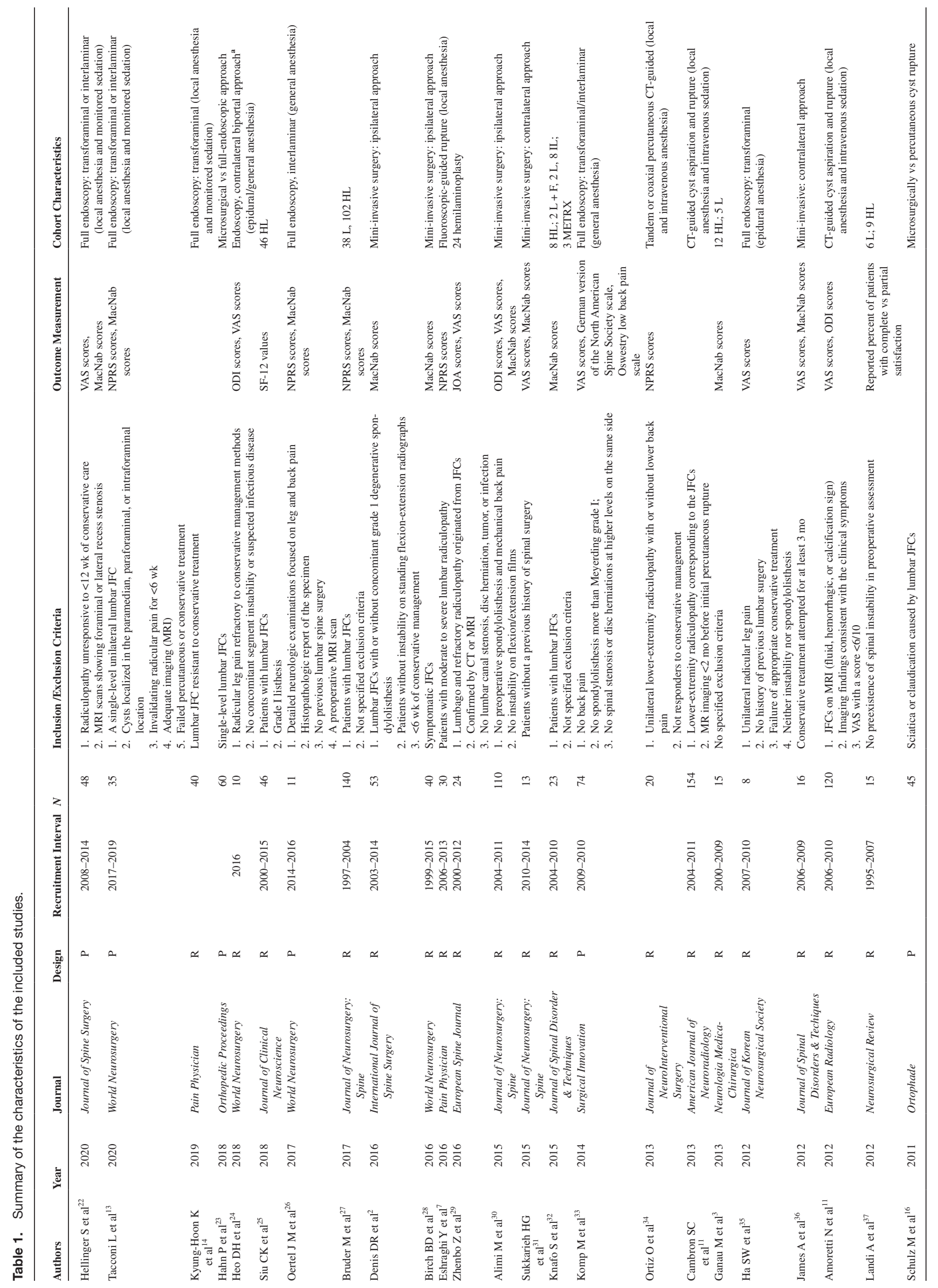


Giordan et al.

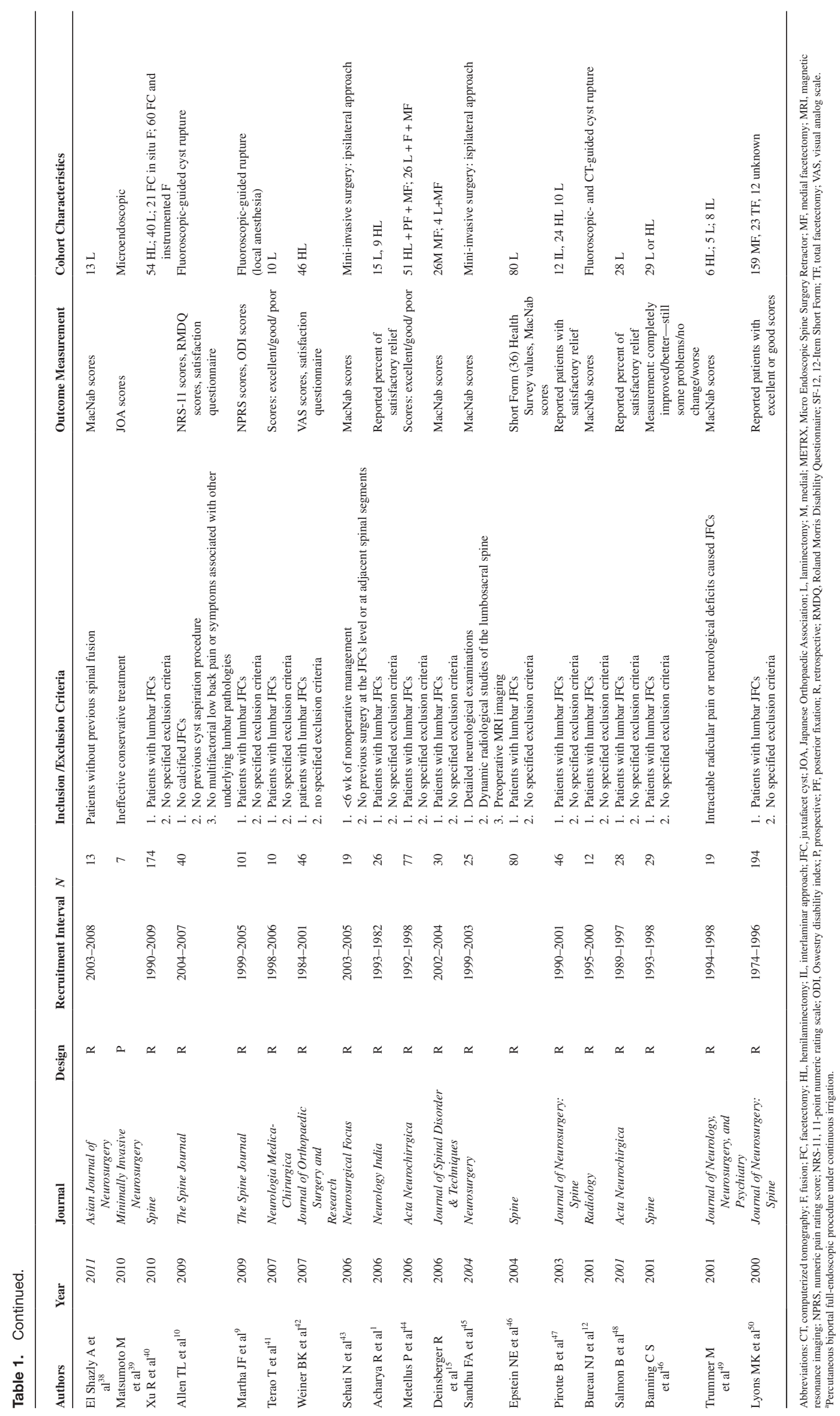




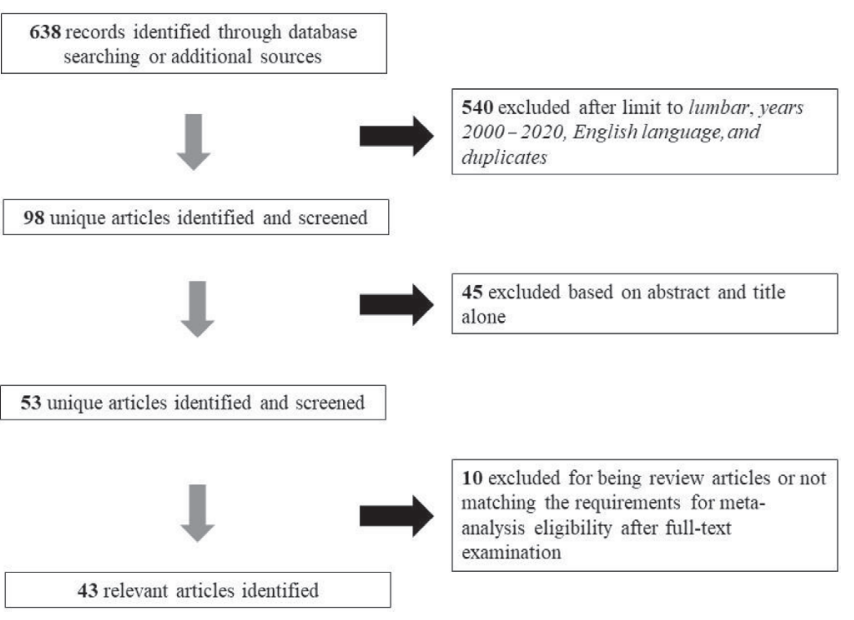

Figure 1. Flow diagram summarizing the process of study selection.

Table 1. Methodological quality indicators are summarized in Table 2. Overall, these noncomparative series appeared to have adequate quality.

\section{Open Surgery}

A total of 21 studies, including 1112 patients $(51.9 \%$ female), were identified. The mean age was 63 years (range 54.4-73 years). L4-L5 was the most affected level $(67.3 \%)$, followed by L3-L4 (16\%), L5-S1 (13.5\%), L2-L3 (2.2\%), and L1-L2 (1.0\%). The average follow-up was 39.5 months (range 8.3-116.4 months). On average, hospital stays ranged from 3 to 7 days. Nineteen studies report the proportion of patients with preoperative degenerative listhesis at the JFC level to be $33.6 \%$.

The most frequently used approach was laminectomy/hemilaminectomy (87.6\%), followed by the interlaminar approach and flavectomy $(7.5 \%)$, and laminectomy and instrumented fusion (4.9\%). A medial facetectomy was usually chosen for cyst excision over a total facetectomy $(5.4 \%$ vs $4.6 \%, P<0.001)$.

Overall, the satisfactory outcome rate after open surgical cysts excision was $93.0 \%$ (95\% CI 88.3\%-96.7\%) (Figure 2), while the surgical adverse event rate was $1.1 \%$ (95\% CI $0.1 \%-3.0 \%$ ). Almost all the intraoperative adverse events were dural tears; only 3 epidural hematoma cases and 1 seroma occurred. Recurrence rate was low, $1.4 \%$ (95\% CI $0.3 \%-3.2 \%)$, and surgical revision rate was $3.0 \%$ (95\% CI $1.3 \%-5.3 \%$ ). The rate of postoperative medical adverse events was negligible $0.1 \%$ (95\% CI $0.0 \%-0.8 \%$ ).

Overall, $5.9 \%$ (95\% CI $0.0 \%-18.2 \%$ ) of patients underwent unplanned intraoperative concomitant fusion in surgery, and 3.5\% (95\% CI 0.6\%-8.0\%) developed overt postoperative instability at the treated level. In the laminectomy group, $8.5 \%$ of patients had recurrence or revision surgery for developing instability at the decompressed level. In contrast, none of the patients who underwent concomitant instrumented fusion experienced recurrences or required additional surgery for developing instability in the follow-up period $(P<$ 0.001).

Comparing satisfactory outcomes between patients with and without preoperative degenerative listhesis (92.7\% [95\% CI $85.7 \%-97.7 \%$ ] vs $93.1 \%$ [95\% CI $89.1 \%-95.6 \%])$, we did not find significant differences $(P=0.854)$. Also, no significant differences in recurrence rates between patients with and without degenerative listhesis were found (2.5\% vs $3.0 \%$, respectively, $P=0.726$ ). However, a significantly higher proportion of patients with preoperative degenerative listhesis required revision surgery than patients without listhesis (6.8\% vs $3.1 \%$, respectively, $P=0.020$ ). The mean time to first intervention and revision surgery ranged from 7.5 to 24 months.

\section{Minimally Invasive Approach}

A total of 8 studies including 279 patients (women $=$ $55.6 \%$; mean age $=65.3$ years, range $62.0-72.4$ years) were identified. The most affected level was L4-L5 (62.2\%), followed by L3-L4 (20.8\%), L5-S1 (12.4\%), and L2-L3 (4.6\%). The average follow-up was 24.0 months (range 11.5-79 months). Hospital stay was consistently reported within 24 hours, while mean operative time was 130 minutes (range 58-184 minutes). Three studies describe a contralateral approach for tubular system insertion and cysts excision, while an ipsilateral method was used in 5. Six studies reported the proportion of patients with preoperative instability at the cyst level: $21.1 \%$.

Overall, favorable outcomes were reported in $82.7 \%$ of patients (95\% CI 61.2\%-97.5\%) (Figure 3), while surgical adverse events rate was $8.4 \%$ (95\% CI $2.7 \%-$ $16.3 \%)$. Most intraoperative adverse events were dural tears, and only 1 case of epidural hematoma occurred. The overall rate of patients who developed some postoperative instability was $3.2 \%$ (95\% CI $0.2 \%-8.4 \%$ ). The overall revision rate was $3.6 \%$ (95\% CI $1.0 \%-$ $2.3 \%)$, while overall recurrence rate was $2.3 \%(95 \%$ CI $0.3 \%-5.5 \%$ ). There was no postoperative medical adversity reported. The mean time to first intervention and revision surgery ranged from 7 to 25.2 months. None of the patients underwent concomitant fusion at the time of intervention.

When comparing outcomes between patients with and without preoperative degenerative listhesis $(77.8 \%$ 
Table 2. Methodological quality evaluation.

\begin{tabular}{|c|c|c|c|c|c|c|}
\hline Authors & Design & $\begin{array}{c}\text { Representatives of } \\
\text { Exposed Cohort }\end{array}$ & $\begin{array}{c}\text { Selection of } \\
\text { Nonexposed Cohort }\end{array}$ & $\begin{array}{c}\text { Ascertainment of } \\
\text { Exposure }\end{array}$ & $\begin{array}{c}\text { Assesment of } \\
\text { Outcome }\end{array}$ & $\begin{array}{c}\text { Length } \\
\text { Follow-Up }\end{array}$ \\
\hline Hellinger $\mathrm{S}$ et $\mathrm{al}^{22}$ & $\bullet$ & $\bullet$ & $\bullet$ & $\bullet \bullet$ & $\bullet \bullet$ & $\bullet$ \\
\hline Tacconi L et al ${ }^{13}$ & $\bullet$ & $\bullet$ & $\bullet$ & $\bullet \bullet$ & $\bullet \bullet$ & \\
\hline Kyung-Hoon $\mathrm{K}$ et al ${ }^{14}$ & & $\bullet$ & & $\bullet$ & & \\
\hline Hahn $\mathrm{P}$ et $\mathrm{al}^{23 *}$ & $\bullet$ & $\bullet \bullet$ & & $\bullet$ & & \\
\hline Heo DH et $\mathrm{al}^{24}$ & & $\bullet$ & & $\bullet$ & $\bullet \bullet$ & $\bullet$ \\
\hline Siu CK et $\mathrm{al}^{25}$ & & $\bullet \bullet$ & $\bullet$ & $\bullet \bullet$ & $\bullet$ & $\bullet$ \\
\hline Oertel JM et $\mathrm{al}^{26}$ & $\bullet$ & $\bullet$ & $\bullet$ & $\bullet \bullet$ & $\bullet \bullet$ & \\
\hline Bruder $\mathrm{M}$ et $\mathrm{al}^{27}$ & & $\bullet \bullet$ & $\bullet$ & $\bullet \bullet$ & $\bullet$ & $\bullet$ \\
\hline Denis DR et $\mathrm{al}^{2}$ & & $\bullet \bullet$ & $\bullet$ & $\bullet \bullet$ & $\bullet$ & \\
\hline Birch BD et $\mathrm{al}^{28}$ & & $\bullet$ & & $\bullet$ & $\bullet$ & $\bullet$ \\
\hline Eshraghi $\mathrm{Y}$ et $\mathrm{al}^{7}$ & & $\bullet$ & & $\bullet$ & $\bullet$ & $\bullet$ \\
\hline Zhenbo $\mathrm{Z}$ et al ${ }^{29}$ & & $\bullet$ & $\bullet$ & $\bullet \bullet$ & $\bullet \bullet$ & $\bullet$ \\
\hline Alimi $\mathrm{M}$ et $\mathrm{al}^{30}$ & & $\bullet \bullet$ & $\bullet$ & $\bullet \bullet$ & $\bullet \bullet \bullet$ & $\bullet$ \\
\hline Sukkarieh HG et al $^{31}$ & & $\bullet$ & $\bullet$ & $\bullet \bullet$ & $\bullet \bullet$ & \\
\hline Knafo $\mathrm{S}$ et $\mathrm{al}^{32}$ & & $\bullet$ & & $\bullet$ & $\bullet$ & \\
\hline Komp M et $\mathrm{al}^{33}$ & $\bullet$ & $\bullet \bullet$ & $\bullet$ & $\bullet \bullet$ & $\bullet \bullet \bullet$ & \\
\hline Ortiz $\mathrm{O}$ et $\mathrm{al}^{51}$ & & $\bullet$ & & $\bullet$ & $\bullet$ & \\
\hline Cambron SC et al ${ }^{11}$ & & $\bullet \bullet$ & & $\bullet \bullet$ & & $\bullet$ \\
\hline Ganau $\mathrm{M}$ et $\mathrm{al}^{3}$ & & $\bullet$ & & $\bullet$ & $\bullet$ & $\bullet$ \\
\hline Ha SW et al ${ }^{35}$ & & $\bullet$ & $\bullet$ & $\bullet \bullet$ & $\bullet$ & \\
\hline James A et $\mathrm{al}^{36}$ & & $\bullet$ & & $\bullet$ & $\bullet \bullet$ & \\
\hline Amoretti $\mathrm{N}$ et $\mathrm{al}^{11}$ & & $\bullet \bullet$ & $\bullet$ & $\bullet \bullet$ & $\bullet \bullet$ & \\
\hline Landi $\mathrm{A}$ et $\mathrm{al}^{37}$ & & $\bullet$ & $\bullet$ & $\bullet \bullet$ & $\bullet$ & \\
\hline Schulz M et $\mathrm{al}^{16}$ & $\bullet$ & $\bullet$ & & $\bullet$ & & $\bullet$ \\
\hline El Shazly A et al ${ }^{38}$ & & $\bullet$ & & $\bullet$ & $\bullet$ & $\bullet$ \\
\hline Matsumoto $\mathrm{M}$ et $\mathrm{al}^{39}$ & $\bullet$ & $\bullet$ & & $\bullet$ & $\bullet$ & $\bullet$ \\
\hline $\mathrm{Xu} \mathrm{R}$ et $\mathrm{al}^{40}$ & & $\bullet \bullet$ & & $\bullet \bullet$ & & \\
\hline Allen TL et al ${ }^{10}$ & & $\bullet$ & $\bullet$ & $\bullet \bullet$ & $\bullet \bullet \bullet$ & \\
\hline Martha JF et al ${ }^{9}$ & & $\bullet$ & & $\bullet$ & $\bullet \bullet$ & $\bullet$ \\
\hline Terao $\mathrm{T}$ et $\mathrm{al}^{41}$ & & $\bullet$ & & $\bullet$ & $\bullet$ & $\bullet$ \\
\hline Weiner BK et $\mathrm{al}^{39}$ & & $\bullet$ & & $\bullet$ & $\bullet \bullet$ & \\
\hline Sehati $\mathrm{N}$ et $\mathrm{al}^{43}$ & & $\bullet$ & & $\bullet \bullet$ & $\bullet$ & \\
\hline Acharya $\mathrm{R}$ et al ${ }^{1}$ & & $\bullet$ & & $\bullet$ & $\bullet$ & \\
\hline Metellus P et al $^{44}$ & & $\bullet \bullet$ & & $\bullet$ & $\bullet$ & $\bullet$ \\
\hline Deinsberger $\mathrm{R}$ et $\mathrm{al}^{15}$ & & $\bullet$ & & $\bullet$ & $\bullet$ & $\bullet$ \\
\hline Sandhu FA et $\mathrm{al}^{45}$ & & $\bullet$ & & $\bullet \bullet$ & $\bullet$ & \\
\hline Epstein NE et $\mathrm{al}^{46}$ & & $\bullet \bullet$ & & $\bullet$ & $\bullet \bullet$ & \\
\hline Pirotte $\mathrm{B}$ et $\mathrm{al}^{47}$ & & $\bullet$ & & $\bullet$ & $\bullet$ & $\bullet$ \\
\hline Bureau NJ et al ${ }^{12}$ & & $\bullet$ & & $\bullet$ & $\bullet$ & \\
\hline Salmon $\mathrm{B}$ et $\mathrm{al}^{48}$ & & $\bullet$ & & $\bullet$ & $\bullet$ & $\bullet$ \\
\hline Banning CS et $\mathrm{al}^{46}$ & & $\bullet$ & & $\bullet$ & $\bullet$ & $\bullet$ \\
\hline Trummer $\mathrm{M}$ et $\mathrm{al}^{49}$ & & $\bullet$ & $\bullet$ & $\bullet$ & $\bullet$ & \\
\hline Lyons $\mathrm{MK}$ et $\mathrm{al}^{50}$ & & $\bullet \bullet$ & & $\bullet$ & $\bullet$ & $\bullet$ \\
\hline
\end{tabular}

Design: One dot for prospective or randomized controlled trials. Representatives of exposed cohort: One dot for study reporting detailed inclusion criteria, two dots for studies reporting detailed inclusion and exclusion criteria. Selection of non-exposed cohort: One dot for each study reporting a control group. Ascertainment of exposure: One dot for the authors confirming the intraoperative presence of a JFC, two dots if the histological confirmation was reported and an accurate JFC description provided. Assesment of outcome: One dot for each different clinical score utilized by authors for measuring postoperative outcomes. Length of follow-up: One dot if the follow-up was more than 24 months.

[95\% CI $46.7 \%-98.4 \%]$ vs $89.7 \%$ [95\% CI $78.8 \%-$ $97.6 \%$, respectively), we found a slight decrease in the unstable patients' outcomes $(P=0.011)$. Also, higher rates of revision surgery $(13.1 \%$ [95\% CI $4.8 \%-24.0 \%]$ vs $3.6 \%$ [95\% CI $0.2 \%-9.4 \%], P=0.004)$ and intraoperative adverse events (31.3\% [95\% CI 18.9\%-45.2\%] vs $4.8 \%$ [95\% CI $1.2 \%-9.9 \%$ ], $P<0.001$ ) were found in the degenerative listhesis group. No differences were found between these 2 groups in terms of recurrence and adverse medical events. No differences in outcomes and adverse events were found when stratifying patients by ipsilateral and contralateral minimally invasive approach.

\section{Full-Endoscopic Approach}

A total of 9 studies, including 263 patients $(52.9 \%$ women, mean age $=49.2$ years, range $=23.1-68.6$ years), were identified. The most affected level was L4-L5 (70.1\%), followed by L5-S1 (19.6\%) and L3-L4 $(10.3 \%)$. The average follow-up was 27.5 months (range 18-55.5 months). Hospital stay was consistently reported to be $<24$ hours, while mean operative time was 60.3 minutes (range 32-78 minutes). Three studies report the proportion of patients with degenerative listhesis at the cyst level to be $8.3 \%$. None of the patients required additional fusion surgery in the follow-up time examined. 


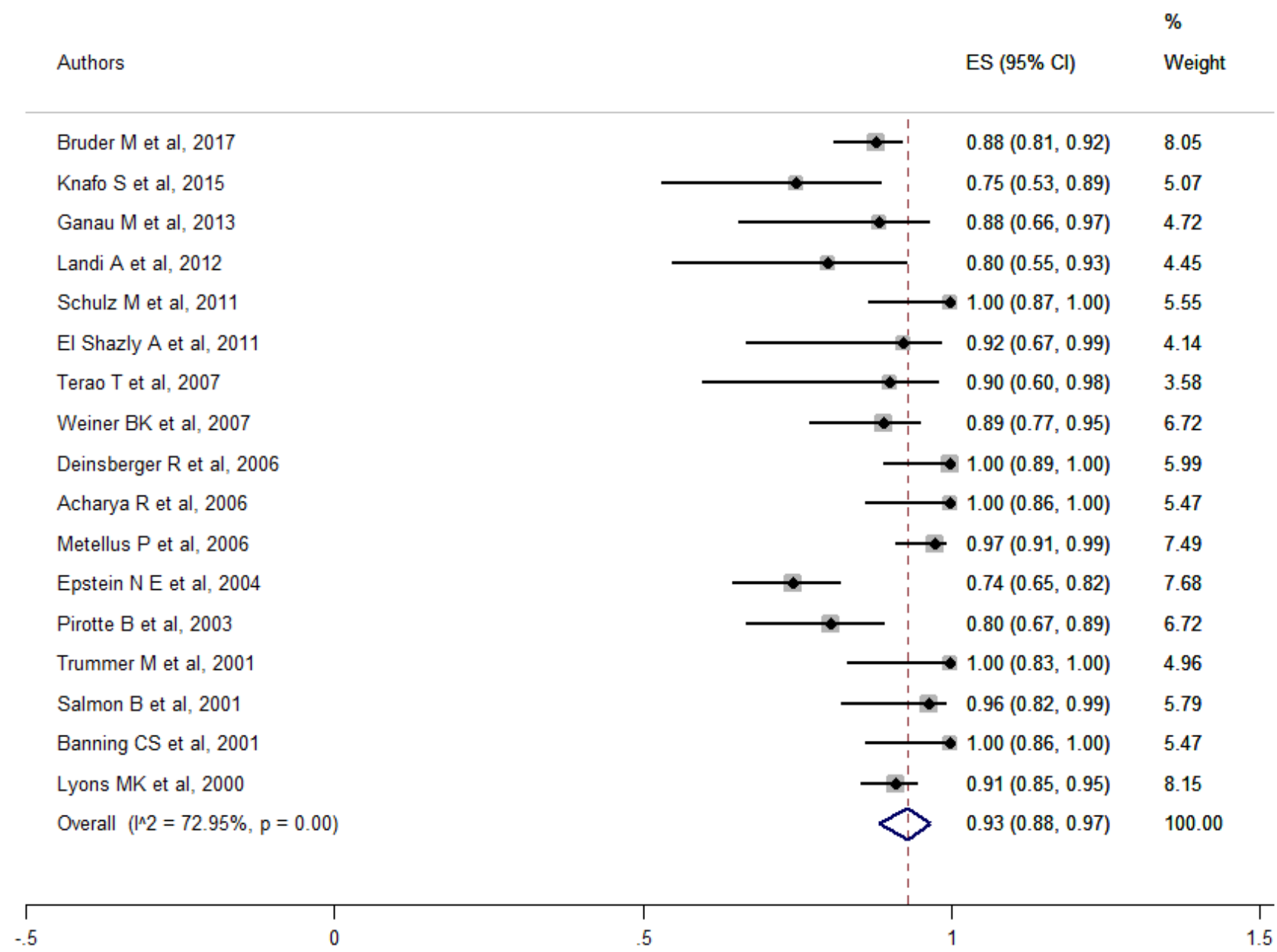

Figure 2. Forest plot for open surgery overall outcomes. ES, effect size.

Overall, favorable outcome after full-endoscopic cysts excision was $90.9 \%$ (95\% CI 83.8\%-96.4\%) (Figure 4), while surgical adverse events rate was $1.8 \%$ (95\% CI $0.0 \%-5.3 \%)$. Except for an epidural hematoma, all the intraoperative adverse events were dural tears, and none required additional intervention for cerebrospinal fluid (CSF) fistula development. The overall JFC recurrence rate was $3.0 \%$ (95\% CI $0.0 \%-9.9 \%)$, while the revision rate was $2.2 \%$ (95\% CI $0.0 \%-8.3 \%)$. There were no postoperative infections or medical complications reported.

\section{Percutaneous Treatment}

A total of 8 studies, including 497 patients (women $=57.8 \%$, mean age $=63.2$ years, range $=58.7-68.2$ years), were identified. In all the studies examined, the JFC aspiration and rupture were attempted, and corticosteroids were locally injected. Five studies reported the caliber of the needle utilized for rupture and aspiration of cyst's content. Four studies used a 22-gauge needle, while one used a 20 -gauge needle. The most affected level was L4-L5 (69.5\%), followed by L5-S1 (16.5\%), L3-L4 (11.6\%), and L2-L3 (2.4\%). The average follow-up was 24.2 months (range 11-44.5 months). On average, hospital stay was less than 1 day. One study reported the proportion of patients with preoperative instability at the cyst level to be $3.9 \%$.

Favorable outcome rate after percutaneous rupture and aspiration was $66.2 \%$ (95\% CI 52.9\%-78.4\%) (Figure 5), while procedural adverse events rate was $0.1 \%$ (95\% CI $0.0 \%-1.2 \%$ ). There were 2 cases of cyst rupture and bleeding in the epidural space. The overall recurrence rate was $34.3 \%$ (95\% CI 20.3\%-49.6\%), and among those, $60.7 \%$ required additional treatment 


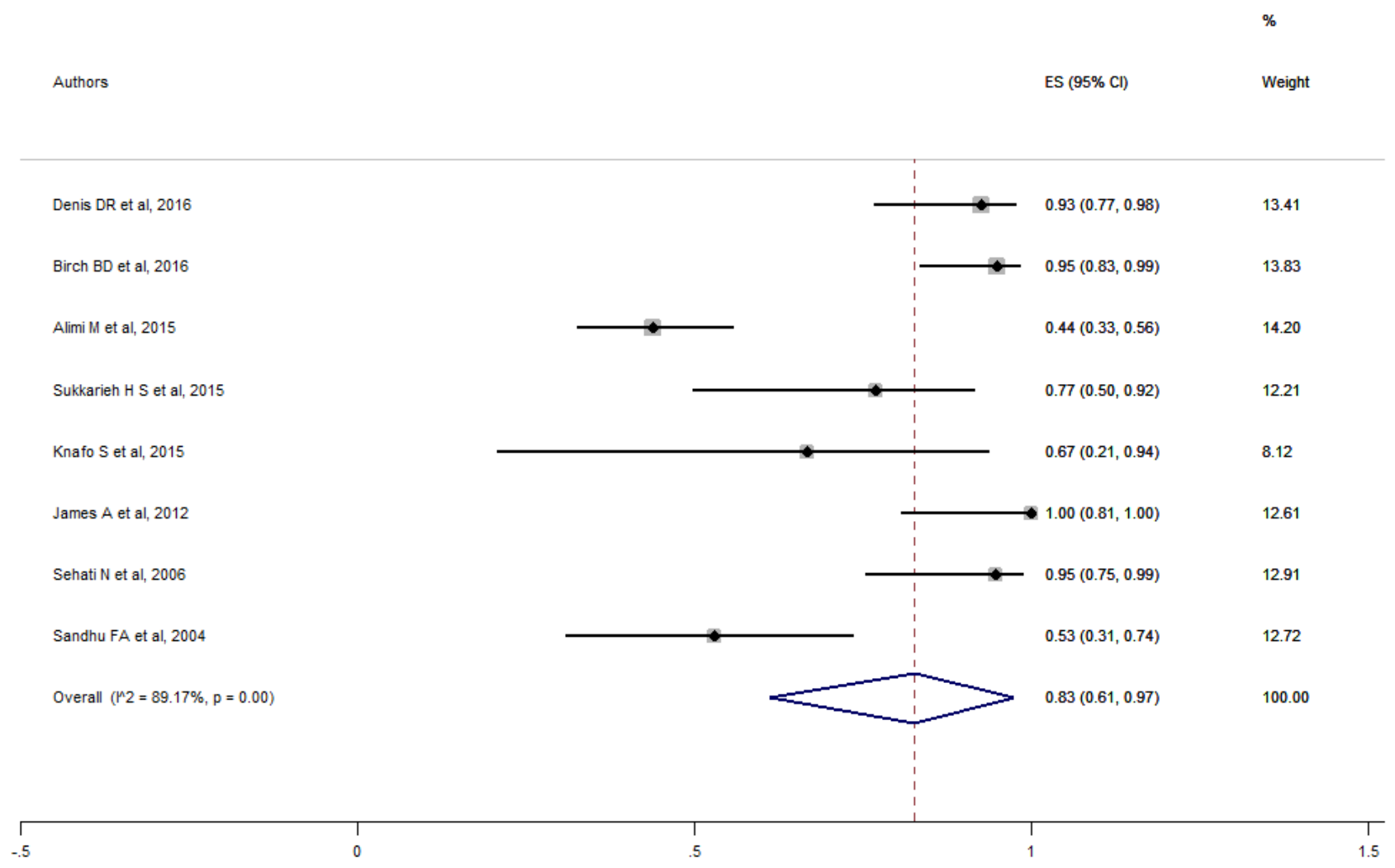

Figure 3. Forest plot for minimally invasive overall outcomes. ES, effect size.

(revision). Of the revision procedures, $47.3 \%$ underwent repeated percutaneous cyst aspiration and rupture, while $52.7 \%$ underwent surgical excision by one of the above mentioned methods. The other recurrences were treated conservatively.

\section{Outcomes and Adverse Events Comparison}

Overall median time from JFC excision to recurrence, excluding patients undergoing concomitant fusion surgery, was 23 months (range 1-60 months; mean $23.6 \pm 20.6$ months). There were no statistically significant differences in overall satisfactory outcomes between patients undergoing open, minimally invasive, and full-endoscopic approaches (Table 3). Statistically, significantly lower satisfaction rates were found between open, minimally invasive, and full-endoscopic approaches and percutaneous cysts rupture and aspiration $(P<0.001)$. Higher recurrence rates were found among percutaneous cyst aspiration and rupture patients than open, minimally invasive, and full endoscopy ones $(P<0.001)$. No differences in overall recurrences rates were found between open and minimally invasive ( $P=$ $0.281)$, open and full-endoscopic $(P=0.072)$, and minimally invasive and full endoscopy $(P=0.612)$ procedures.

No differences in overall revision rates were found between open and minimally invasive $(P=0.606)$, open and full-endoscopic $(P=0.483)$, and minimally invasive and full endoscopy procedures $(P=0.334)$. Percutaneous cysts rupture and aspiration recurrences and revision rates were significantly higher than all other procedures $(P<0.001)$. No differences in postoperative instability rates were found between open and minimally invasive approaches $(P=0.806)$.

No differences in overall surgical adverse event rates were found between open and full-endoscopic procedures $(P=0.355)$ but higher rates between minimally invasive and open $(P<0.001)$ and full-endoscopic procedures $(P=0.001)$. As expected, procedural adverse events were significantly lower for percutaneous cysts rupture and aspiration than open, minimally invasive, and full-endoscopic procedures $(P=0.001)$. 


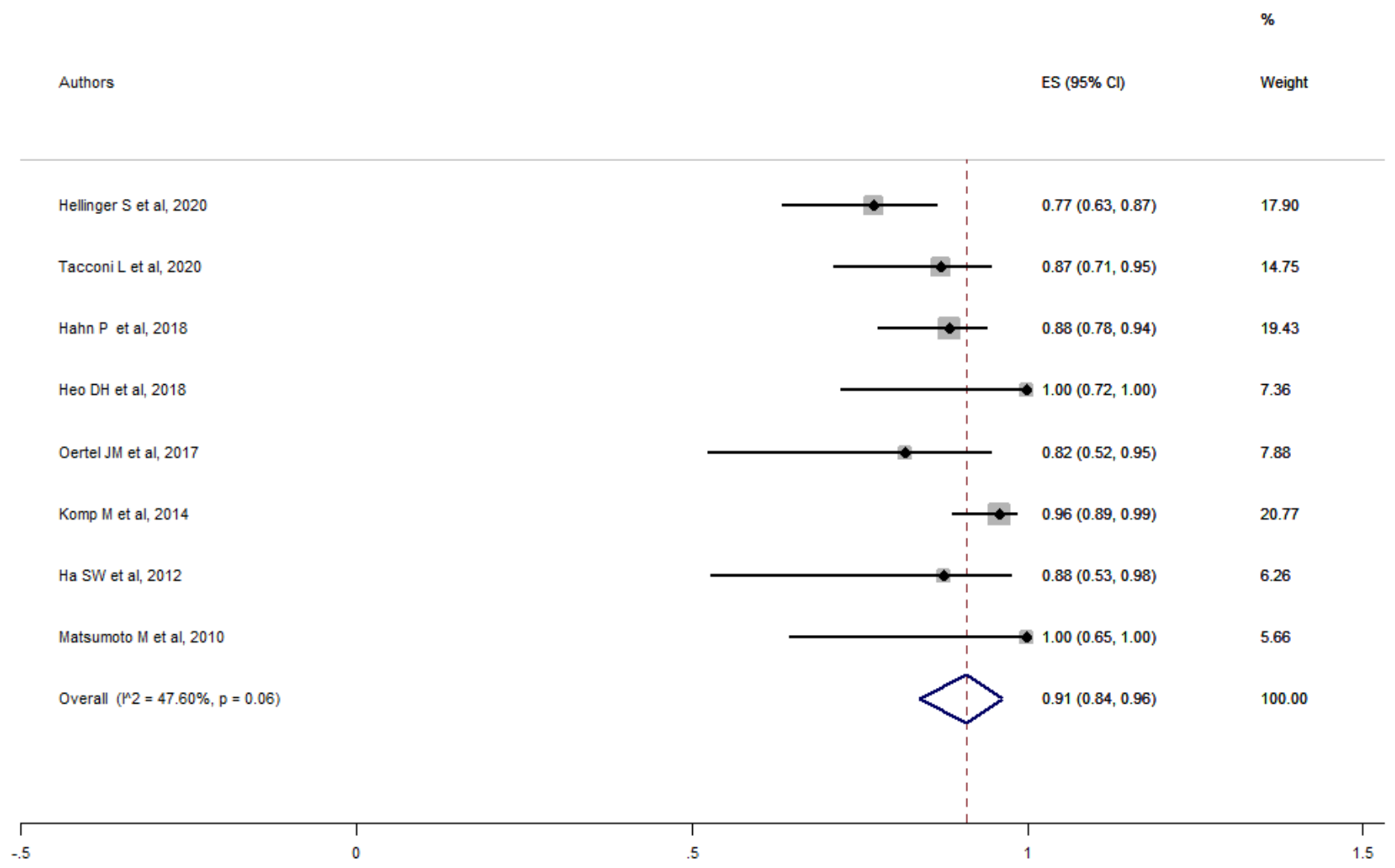

Figure 4. Forest plot for full endoscopy overall outcomes. ES, effect size.

In our subgroup analysis (patients with preoperative degenerative listhesis vs without preoperative degenerative listhesis), open and minimally invasive surgery was used more than full-endoscopic and percutaneous procedures among patients with preoperative degenerative listhesis $(P=0.001$, respectively). We additionally found lower rates of satisfactory outcomes in patients with preoperative degenerative listhesis undergoing minimally invasive approaches compared to open surgical approaches $(77.8 \%$ vs $92.7 \%, P<0.001)$ but higher rates of adverse surgical events $(31.3 \%$ vs $2.1 \%$, $P<0.001)$ and of patients requiring revision surgery $(13.1 \%$ vs $6.8 \%, P$ value $=0.042)$.

\section{DISCUSSION}

To the best of our knowledge, this is the most upto-date systematic review and meta-analysis on outcomes and complications of lumbar JFC treatment. We estimated overall outcomes and adverse event rates for each surgical procedure, including percutaneous-guided cysts rupture and aspiration. We also stratified results based on preoperative spinal stability conditions. This was done to provide a better insight into JFCs treatment, especially for open and minimally invasive procedures.

Overall, we did not find significant differences in outcomes between open, minimally invasive, and fullendoscopic cysts excision but lower satisfactory rates in patients undergoing percutaneous cysts rupture and aspiration as well as higher recurrences and revision rates. After stratifying results between patients with and without preoperative degenerative listhesis, we found slightly lower satisfactory rates but higher intraoperative adverse events and revision rates in patients with degenerative listhesis at the cyst level. Revision and adverse event rates, mainly attributable to dural tears, were higher in patients undergoing minimally invasive surgery and carrying preoperative degenerative listhesis.

Laminectomy/Hemilaminectomy has shown satisfactory outcomes in approximately $90 \%$ of patients over 6 months of follow-up, ${ }^{6,29,37,44,46-48,50,52}$ though some patients still require concomitant fusion because 


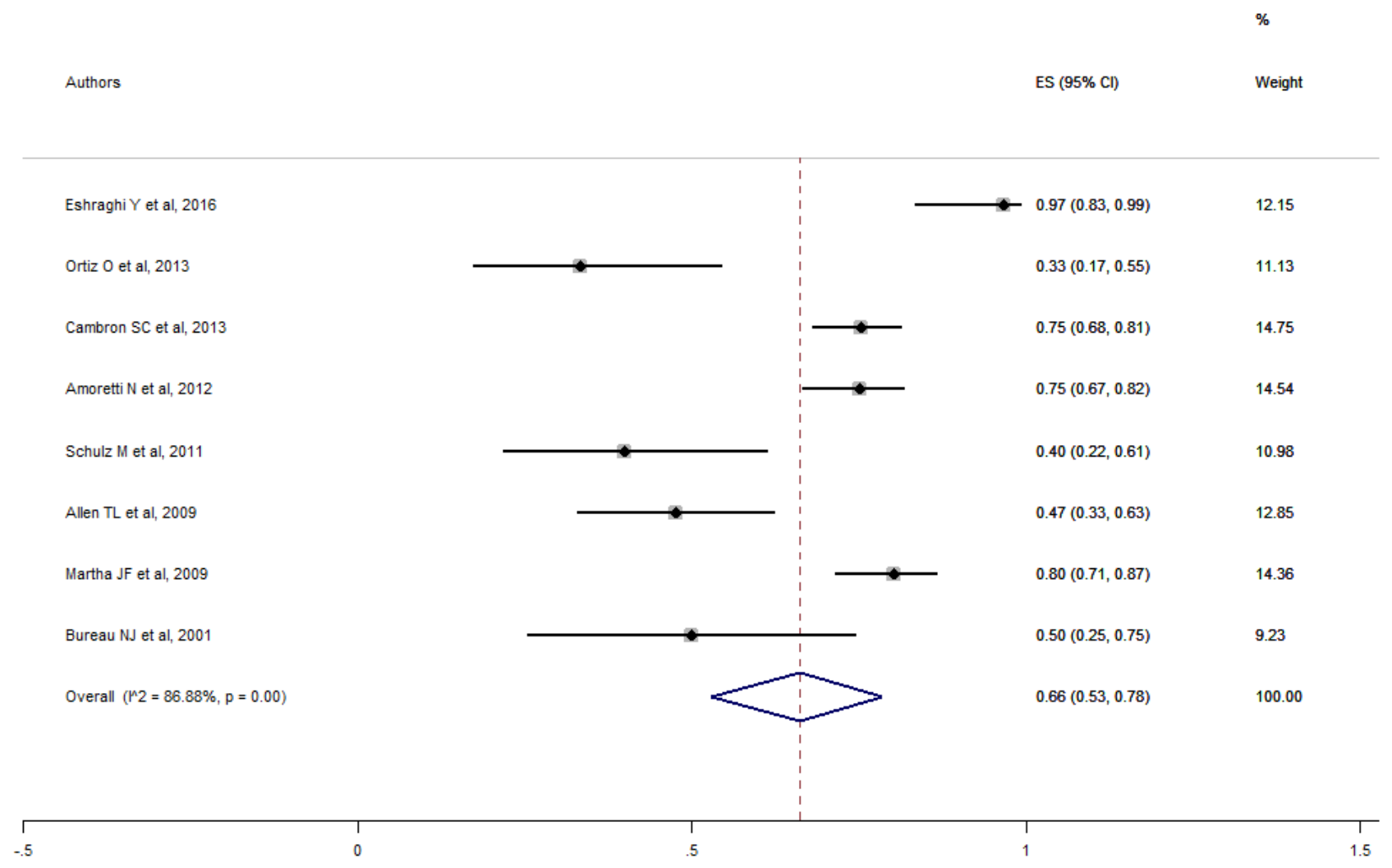

Figure 5. Forest plot for percutaneous fluoroscopic- or CT-guided overall outcomes. ES, effect size.

of preoperative instability while others required subsequent fusion due to the development of postoperative instability. ${ }^{25,27,38,50}$

Cystectomy alone may be enough for back/leg pain relief in $90 \%$ of patients, at least initially. However, decompression alone in the presence of underlying segmental instability may predispose cyst recurrence. $^{28,29,40,42}$ Of note, same-site recurrence was never reported in any patients receiving concomitant spinal fusion. . $^{6,40,41,52}$

JFC recurrence was higher in the laminectomy/ hemilaminectomy patients than in patients undergoing fusion. Patients with preoperative degenerative listhesis have almost twice the risk of recurrence or revision surgery due to developing instability at the treated level. ${ }^{8,49}$ However, indiscriminate fusion might aggravate adjacent level degeneration ${ }^{53}$ while raising perioperative morbidity, extending hospital stay, and resulting in a higher risk of incidental durotomy and greater blood loss. ${ }^{25,27,32,54}$
Minimally invasive surgery aims to preserve the dorsal muscular and ligamentous attachments that are paramount for spinal stability. ${ }^{30,31,36,43}$ It has been shown to have successful outcomes over the short- and long-term in $95 \%$ of patients. ${ }^{43}$ However, the tubular approach is challenging and burdened with a higher risk of durotomy, epidural hematoma, and CSF leak in nonexperienced hands. This may be explained by the limited field of view and steep learning curve. Also, cysts adherent to the dural sheath can make dissection demanding. ${ }^{45}$ These factors may explain the higher revision and adverse event rates among patients with preoperative degenerative listhesis.

Eventually, full-endoscopic techniques have reported satisfactory outcomes in treating symptomatic JFC cysts in the vast majority of cases over a mean follow-up period of $<24$ months. ${ }^{22,23,35}$ However, it is clear from our analysis by the significantly lower percentage of patients with preoperative degenerative listhesis than open or minimally invasive approaches that endoscopic patients were carefully selected in each series. ${ }^{33}$ Full 


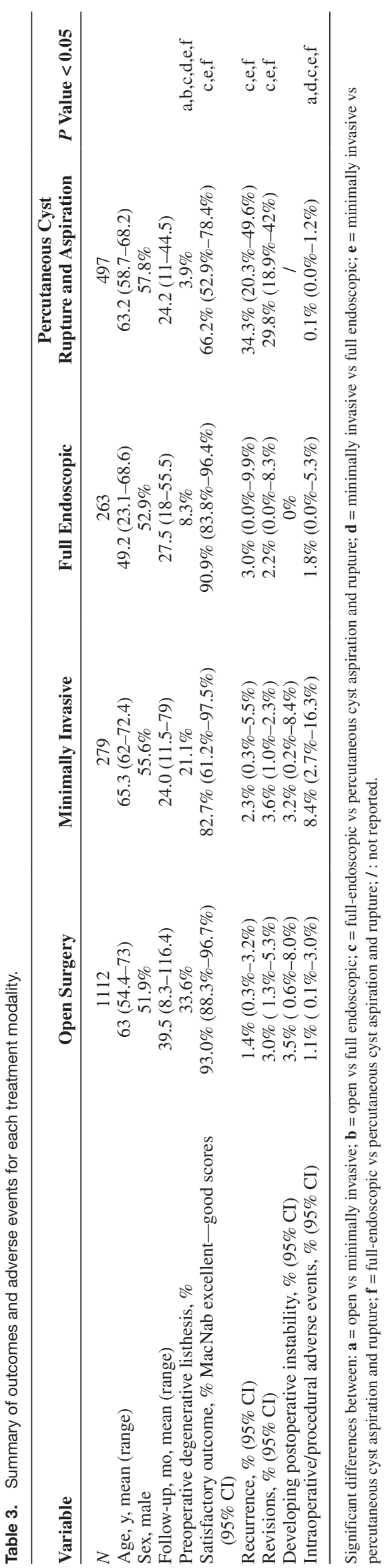


endoscopy, especially the transforaminal approach, is associated with milder surgical trauma, ${ }^{24}$ shorter operating time, negligible blood loss and CSF leakage, mild postoperative back pain, and shorter hospitalization time. $^{13}$

New instruments (eg, shavers and diamond burrs) provide adequate bone resection and make cyst removal technically feasible, ${ }^{26}$ but the learning curve is steep, and appropriate training is paramount for success. ${ }^{39}$

The minimally invasive technique offers similar results compared to open surgery at the cost of slightly higher adverse event rates in patients with preoperative degenerative listhesis. A trend toward higher adverse event rates, particularly postoperative nerve roots paresthesia, is similarly reported by studies comparing minimally invasive to open lumbar surgery ${ }^{51}$. By pooling such a large number of patients in subgroup analysis, we were able to confirm this trend. Our minimally invasive group results reflect a higher challenging procedure in more degenerate segments, speculatively consequent to a limited field of view and surgical freedom (instruments) inside a narrowed space leading to significant nerve root traction and manipulation compared to open surgery. Similar results may have been found in the fullendoscopic groups; however, the procedure's novelty and the stricter patient selection precluded most of the patients with degenerative degenerate segments at the cyst level to undergo endoscopy. It would be interesting to evaluate such occurrences in future analyses.

By comparison, full-endoscopic JFC excision is even less traumatic and more respectful of the articular process integrity. ${ }^{34}$ Indeed, the transforaminal approach allows root and foraminal decompression without compromising spinal stability and without scar formation developing. ${ }^{55}$ Thus, it is feasible to control symptoms even in mild spinal instability. Eventually, laminectomy/hemilaminectomy and fusion should be reserved in overt spinal instability cases or when total facetectomy is required for cyst excision (ie, in recurrent cases), while percutaneous cyst rupture and aspiration to patients not suited or unwilling to undergoing invasive procedures.

\section{Limitations}

The main limitation is the lack of individual patient data, which makes prognostic analysis subject to confounding bias and limits our ability to stratify outcomes. Findings may also have been impacted by inter- and intraobserver variability in assessing the prevalence of clinical improvement, especially regarding "excellent" and "good" outcomes.
Additionally, not all the studies report every outcome evaluated in this review. Although this may have impacted the results, every attempt was made to account for heterogeneity using statistical methods. Moreover, only 5 studies were estimated to have an elevated risk of bias. Additionally, it may be argued that those cases chosen to be treated with minimally invasive or full endoscopic procedures may not be the same as treated with a conventional open procedure. Also, there is an inherent bias in the studies pooled in the meta-analysis. Many of the studies, especially minimally invasive and endoscopic, may be biased toward those procedures, thus introducing a selection bias. However, we carefully evaluated the existing literature and relative methodological flaws to account for missing information and unanswered questions relating to JFCs treatment. Considering JFCs treatments' heterogeneity, such an extensive analysis is virtually impossible without a meta-analysis process, which allows for group comparison. Therefore, the studies included in this meta-analysis were selected following a strict a priori established protocol, the literature search included multiple databases, and study selection was rigorous and based on the criteria established by the most recent guidelines. Eventually, in the meta-analysis, only studies with homogenous outcomes were included (objective and validated outcomes as described in the Methods section), excluding those who were uncertain or derived from a subjective surgeon evaluation.

\section{CONCLUSIONS}

Besides confirming the safety and efficacy of open and minimally invasive approaches, we highlighted how full endoscopy has outcomes, rates of adverse events, and operative times that overlap those of the open and minimally invasive approaches. We believe that the spine surgeon's wealth of knowledge must include all of these techniques. These results may help the surgeon in the reasoning process of each case.

\section{REFERENCES}

1. Acharya R, Patwardhan RV, Smith DR, Willis BK, Fowler M, Nanda A. Intraspinal synovial cysts: a retrospective study. Neurol India. 2006;54(1):38-41. doi:10.4103/0028-3886.24700

2. Denis DR, Hirt D, Shah S, Lu DC, Holly LT. Minimally invasive surgery for lumbar synovial cysts with coexisting degenerative spondylolisthesis. Int J Spine Surg. 2016;10:37. doi:10.14444/3037

3. Ganau M, Ennas F, Bellisano G, et al. Synovial cysts of the lumbar spine--pathological considerations and surgical strategy. Neurol Med Chir. 2013;53(2):95-102. doi:10.2176/nmc.53.95

4. Knox AM, Fon GT. The appearances of lumbar intraspinal synovial cysts. Clin Radiol. 1991;44(6):397-401. doi:10.1016/ s0009-9260(05)80658-0 
5. Cambron SC, McIntyre JJ, Guerin SJ, Li Z, Pastel DA. Lumbar facet joint synovial cysts: does T2 signal intensity predict outcomes after percutaneous rupture? AJNR Am J Neuroradiol. 2013;34(8):1661-1664. doi:10.3174/ajnr.A3441

6. Bydon M, Papadimitriou K, Witham T, et al. Treatment of spinal synovial cysts. World Neurosurg. 2013;79(2):375-380. doi:10.1016/j.wneu.2012.08.016

7. Eshraghi Y, Desai V, Cajigal Cajigal C, Tabbaa K. Outcome of percutaneous lumbar synovial cyst rupture in patients with lumbar radiculopathy. Pain Physician. 2016;19(7):E1019-25

8. Campbell RJ, Mobbs RJ, Rao PJ, Phan K. Interventions for lumbar synovial facet joint cysts: a comparison of percutaneous. Surgical Decompression and Fusion Approaches World Neurosurg. 2017;98:492-502. doi:10.1016/j.wneu.2016.11.044

9. Martha JF, Swaim B, Wang DA, et al. Outcome of percutaneous rupture of lumbar synovial cysts: a case series of 101 patients. Spine J. 2009;9(11):899-904. doi:10.1016/j.spinee.2009.06.010

10. Allen TL, Tatli Y, Lutz GE. Fluoroscopic percutaneous lumbar zygapophyseal joint cyst rupture: a clinical outcome study. Spine J. 2009;9(5):387-395. doi:10.1016/j.spinee.2008.08.008

11. Amoretti N, Huwart L, Foti P, et al. Symptomatic lumbar facet joint cysts treated by CT-guided intracystic and intraarticular steroid injections. Eur Radiol. 2012;22(12):2836-2840. doi:10.1007/s00330-012-2533-z

12. Bureau NJ, Kaplan PA, Dussault RG. Lumbar facet joint synovial cyst: percutaneous treatment with steroid injections and distention--clinical and imaging follow-up in 12 patients. Radiology. 2001;221(1):179-185. doi:10.1148/radiol.2211010213

13. Tacconi L, Spinelli R, Serra G, Signorelli F, Giordan E. Full-endoscopic removal of lumbar juxtafacet cysts: a prospective multicentric study. World Neurosurg. 2020;141:e414-e422. doi:10.1016/j.wneu.2020.05.166

14. Kim K-H, Kim S-Y, Ok H-G, Kim T-K. A staged treatment of symptomatic lumbar intraspinal synovial cysts. Pain Physician. 2019;22(5):E451-E456. doi:10.36076/ppj/2019.22.E451

15. Deinsberger R, Kinn E, Ungersböck K. Microsurgical treatment of juxta facet cysts of the lumbar spine. J Spinal Disord Tech. 2006;19(3):155-160. doi:10.1097/01.bsd.0000188660. 31212.83

16. Schulz C, Danz B, Waldeck S, Kunz U, Mauer UM. Perkutane CT-gesteuerte destruktion vs. mikrochirurgische resektion lumbaler juxtafacettzysten. Orthopäde. 2011;40(7):600-606. doi:10.1007/s00132-011-1744-3

17. Themistoklis KM, Papasilekas TI, Boviatsis KA, et al. Spinal synovial cysts. A case series and current treatment options. $J$ Clin Neurosci. 2018;57:173-177. doi:10.1016/j.jocn.2018.08.038

18. Lasanianos NG, Triantafyllopoulos GK, Pneumaticos SG. Spondylolisthesis grades. In: Lasanianos NG, Kanakaris NK, Giannoudis PV, eds. Trauma and Orthopaedic Classifications: A Comprehensive Overview. London: Springer; 2015:239-242. doi:10.1007/978-1-4471-6572-9

19. Macnab I. Negative disc exploration. An analysis of the causes of nerve-root involvement in sixty-eight patients. $J$ Bone Joint Surg Am. 1971;53(5):891-903. doi:10.2106/00004623197153050-00004

20. Murad MH, Sultan S, Haffar S, Bazerbachi F. Methodological quality and synthesis of case series and case reports. BMJ Evid Based Med. 2018;23(2):60-63. doi:10.1136/bmjebm-2017-110853

21. Hutton B, Salanti G, Caldwell DM, et al. The PRISMA extension statement for reporting of systematic reviews incorporating network meta-analyses of health care interventions: checklist and explanations. Ann Intern Med. 2015;162(11):777-784. doi:10.7326/ M14-2385

22. Hellinger S, Lewandrowski KU. Clinical outcomes with endoscopic resection of lumbar extradural cysts. J Spine Surg. 2020;6(Suppl 1):S133-S144. doi:10.21037/jss.2019.08.08

23. Hahn P, Komp M, Merk H, Godolias G, Ruetten S. Surgical treatment of lumbar juxtafacet cyst with full endoscopic interlaminar and trans-/extraforaminal approachprospective randomized controlled study with 60 patients. Orthop Proc. 2012;94-B(SUPP_XXXVII):392. doi:10.1302/1358 992X.94BSUPP_XXXVII.EFORT2011-392

24. Heo DH, Kim JS, Park CW, Quillo-Olvera J, Park CK. Contralateral sublaminar endoscopic approach for removal of lumbar juxtafacet cysts using percutaneous biportal endoscopic surgery: technical report and preliminary results. World Neurosurg. 2019;122:474-479. doi:10.1016/j.wneu.2018.11.072

25. Siu KC, Stoodley MA. Decompressive laminectomy without fusion for lumbar facet joint cysts. J Clin Neurosci. 2018;58(August 2000):113-116. doi:10.1016/j.jocn.2018.09.013

26. Oertel JM, Burkhardt BW. Endoscopic surgical treatment of lumbar synovial cyst: detailed account of surgical technique and report of 11 consecutive patients. World Neurosurg. 2017;103:122-132. doi:10.1016/j.wneu.2017.02.075

27. Bruder M, Cattani A, Gessler F, et al. Synovial cysts of the spine: long-term follow-up after surgical treatment of 141 cases in a single-center series and comprehensive literature review of 2900 degenerative spinal cysts. J Neurosurg Spine. 2017;27(3):256-267. doi:10.3171/2016.12.SPINE16756

28. Birch BD, Aoun RJN, Elbert GA, Patel NP, Krishna C, Lyons MK. Minimally invasive tubular resection of lumbar synovial cysts: report of 40 consecutive cases. World Neurosurg. 2016;94:188-196. doi:10.1016/j.wneu.2016.06.125

29. Zhenbo Z, Huanting L, Jin W, Haifeng G, Yuan F, Ming L. Hemilaminoplasty for the treatment of lumbar intraspinal synovial cysts (LISCs) and literature review. Eur Spine J. 2016;25(11):3393-3402. doi:10.1007/s00586-014-3570-x

30. Alimi M, Hofstetter CP, Pyo SY, Paulo D, Härtl R. Minimally invasive laminectomy for lumbar spinal stenosis in patients with and without preoperative spondylolisthesis: clinical outcome and reoperation rates. J Neurosurg Spine. 2015;22(4):339-352. doi:10.3171/2014.11.SPINE13597

31. Sukkarieh HG, Hitchon PW, Awe O, Noeller J. Minimally invasive resection of lumbar intraspinal synovial cysts via a contralateral approach: review of 13 cases. J Neurosurg Spine. 2015;23(4):444-450. doi:10.3171/2015.1.SPINE14996

32. Knafo S, Page P, Pallud J, Roux FX, Abi-Lahoud G. Surgical management of spinal synovial cysts: a series of 23 patients and systematic analysis of the literature. J Spinal Disord Tech. 2015;28(6):211-217. doi:10.1097/BSD.0b013e31827179c8

33. Komp M, Hahn P, Ozdemir S, et al. Operation of lumbar zygoapophyseal joint cysts using a full-endoscopic interlaminar and transforaminal approach: prospective 2-year results of 74 patients. Surg Innov. 2014;21(6):605-614. doi:10.1177/1553350614525668

34. Ortiz AO, Tekchandani L. Improved outcomes with direct percutaneous CT guided lumbar synovial cyst treatment: advanced approaches and techniques. J Neurointerv Surg. 2014;6(10):790-794. doi:10.1136/neurintsurg-2013-010891

35. Ha SW, Ju CI, Kim SW, Lee S, Kim YH, Kim HS. Clinical outcomes of percutaneous endoscopic surgery for lumbar discal cyst. J Korean Neurosurg Soc. 2012;51(4):208-214. doi:10.3340/ jkns.2012.51.4.208 
36. James A, Laufer I, Parikh K, Nagineni VV, Saleh TO, Härtl R. Lumbar juxtafacet cyst resection: the facet sparing contralateral minimally invasive surgical approach. J Spinal Disord Tech. 2012;25(2):E13-7. doi:10.1097/BSD.0b013e31822ac4e5

37. Landi A, Marotta N, Tarantino R, et al. Microsurgical excision without fusion as a safe option for resection of synovial cyst of the lumbar spine: long-term follow-up in mono-institutional experience. Neurosurg Rev. 2012;35(2):245-253. doi:10.1007/s10143011-0356-Z

38. El Shazly AA, Khattab MF. Surgical excision of a Juxtafacet cyst in the lumbar spine: a report of thirteen cases with long-term follow up. Asian J Neurosurg. 2011;6(2):78-82. doi:10.4103/17935482.92162

39. Matsumoto M, Watanabe K, Tsuji T, et al. Microendoscopic resection of lumbar discal cysts. Minim Invasive Neurosurg. 2010;53(2):69-73. doi:10.1055/s-0030-1249052

40. Xu R, McGirt MJ, Parker SL, et al. Factors associated with recurrent back pain and cyst recurrence after surgical resection of one hundred ninety-five spinal synovial cysts: analysis of one hundred sixty-seven consecutive cases. Spine. 2010;35(10):1044-1053. doi:10.1097/BRS.0b013e3181bdafed

41. Terao T, Takahashi H, Taniguchi M, et al. Clinical characteristics and surgical management for juxtafacet cysts of the lumbar spine. Neurol Med Chir. 2007;47(6):250-257. doi:10.2176/ nmc. 47.250

42. Weiner BK, Torretti J, Stauff M. Microdecompression for lumbar synovial cysts: an independent assessment of long term outcomes. J Orthop Surg Res. 2007;2(1):3-7. doi:10.1186/1749799X-2-5

43. Sehati N, Khoo LT, Holly LT. Treatment of lumbar synovial cysts using minimally invasive surgical techniques. Neurosurg Focus. 2006;20(3):1-6. doi:10.3171/foc.2006.20.3.3

44. Métellus P, Fuentes S, Adetchessi T, et al. Retrospective study of 77 patients harbouring lumbar synovial cysts: functional and neurological outcome. Acta Neurochir. 2006;148(1):47-54. doi:10.1007/s00701-005-0650-z

45. Sandhu FA, Santiago P, Fessler RG, Palmer S. Minimally invasive surgical treatment of lumbar synovial cysts. Neurosurgery. 2004;54(1):107-111. doi:10.1227/01.neu.0000097269.79994.2f

46. Banning CS, Thorell WE, Leibrock LG. Patient outcome after resection of lumbar juxtafacet cysts. Spine. 2001;26(8):969-972. doi:10.1097/00007632-200104150-00024

47. Pirotte B, Gabrovsky N, Massager N, Levivier M, David P, Brotchi J. Synovial cysts of the lumbar spine: surgery-related results and outcome. J Neurosurg. 2003;99(1 Suppl):14-19. doi:10.3171/ spi.2003.99.1.0014

48. Salmon B, Martin D, Lenelle J, Stevenaert A. Juxtafacet cyst of the lumbar spine. Clinical, radiological and therapeutic aspects in 28 cases. Acta Neurochir. 2001;143(2):129-134. doi:10.1007/s007010170117

49. Trummer M, Flaschka G, Tillich M, Homann CN, Unger F, Eustacchio S. Diagnosis and surgical management of intraspinal synovial cysts: report of 19 cases. J Neurol Neurosurg Psychiatry. 2001;70(1):74-77. doi:10.1136/jnnp.70.1.74
50. Lyons MK, Atkinson JLD, Wharen RE, Deen HG, Zimmerman RS, Lemens SM. Surgical evaluation and management of lumbar synovial cysts: the Mayo Clinic experience. J Neurosurg. 2000;93(1 Suppl):53-57. doi:10.3171/spi.2000.93.1.0053

51. Epstein NE. More nerve root injuries occur with minimally invasive lumbar surgery: let's tell someone. Surg Neurol Int. 2016;7(Suppl 3):S96-S101. doi:10.4103/2152-7806.174896

52. Epstein NE, Baisden J. The diagnosis and management of synovial cysts: efficacy of surgery versus cyst aspiration. Surg Neurol Int. 2012;3(Suppl 3):S157-66. doi:10.4103/2152-7806.98576

53. Bydon A, Xu R, Parker SL, et al. Recurrent back and leg pain and cyst reformation after surgical resection of spinal synovial cysts: systematic review of reported postoperative outcomes. Spine J. 2010;10(9):820-826. doi:10.1016/j.spinee.2010.04.010

54. Khan AM, Girardi F. Spinal lumbar synovial cysts. Diagnosis and management challenge. Eur Spine J. 2006;15(8):1176-1182. doi:10.1007/s00586-005-0009-4

55. Tacconi L, Signorelli F, Giordan E. Is full endoscopic lumbar discectomy less invasive than conventional surgery? A randomized MRI study. World Neurosurg. 2020;138:e867-e875. doi:10.1016/j.wneu.2020.03.123

Funding: The author(s) received no financial support for the research, authorship, and/or publication of this article.

\section{Financial Disclosures and Conflicts of}

Interest: All authors certify that they have no affiliations with or involvement in any organization or entity with any financial interest (such as honoraria; educational grants; participation in speakers' bureaus; membership, employment, consultancies, stock ownership, or other equity interest; and expert testimony or patentlicensing arrangements), or non-financial interest (such as personal or professional relationships, affiliations, knowledge or beliefs) in the subject matter or materials discussed in this manuscript.

Corresponding Author: Enrico Giordan, Department of Neurosurgery, Aulss 2 Marca Trevigiana, Via Piazzale 1, Treviso 31100, Italy; enrico. giordan@aulss2.veneto.it

Published 21 February 2022

This manuscript is generously published free of charge by ISASS, the International Society for the Advancement of Spine Surgery. Copyright (C) 2022 ISASS. To see more or order reprints or permissions, see http:// ijssurgery.com. 